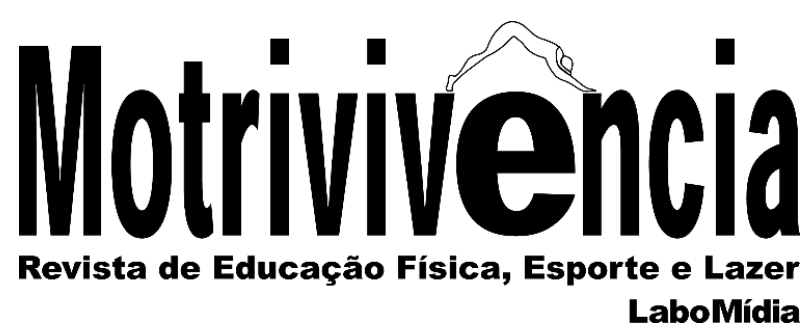

\title{
Implementação de políticas públicas: a organização do esporte e lazer no Programa Novo Mais Educação na rede municipal de educação de Ponta Grossa - Paraná (2017)
}

\section{RESUMO}

O presente estudo tem por objetivo compreender a organização para a implementação do esporte e lazer no Programa Novo Mais Educação na Rede Municipal de Educação de Ponta Grossa - Paraná (2017). Para tanto, utiliza-se das estratégias de Estudo de Caso (YIN, 2005) e Análise de Conteúdo (BARDIN, 2011). Desse modo, observa-se que quatro escolas não receberam o programa, sendo que uma delas encaixava-se nos critérios preferenciais de seleção. As atividades do núcleo optativo do 'Campo de Arte e Cultura' foram mais escolhidas pelos gestores das escolas se comparadas às de 'Esporte e Lazer'. Dentre as atividades mais escolhidas, destacam-se a dança, judô e xadrez. O que permite concluir que todas as escolas optaram por alguma atividade da Cultura Corporal.

Palavras-chave: Implementação; Políticas Públicas; Esporte; Lazer.

PALAVRAS-CHAVE: Implementação; Políticas públicas; Esporte; Lazer.
Diego Petyk de Sousa

Mestre em Ciências Sociais Aplicadas Universidade Estadual de Ponta Grossa - UEPG Departamento de Educação Física Ponta Grossa, Paraná, Brasil diegopetyk@uol.com.br (D) https://orcid.org/0000-0002-2234-7342

Érica Fernanda de Paula Mestre em Ciências Sociais Aplicadas Universidade Estadual de Ponta Grossa - UEPG

Departamento de Educação Física

Ponta Grossa, Paraná, Brasil erydepaula@hotmail.com

(D) https://orcid.org/0000-0002-3702-3156

Mariana Ciminelli Maranho Doutora em Ciências Sociais Aplicadas Instituto Federal do Paraná - IFPR

Campus Telêmaco Borba

Telêmaco Borda, Paraná, Brasil maranho.mari@gmail.com

(D) https://orcid.org/0000-0002-5603-1485

Alfredo Cesar Antunes Doutor em Educação Física Universidade Estadual de Ponta Grossa - UEPG

Departamento de Educação Física

Ponta Grossa, Paraná, Brasil

alfredo.cesar@hotmail.com

(1) https://orcid.org/0000-0001-9446-5316

Constantino Ribeiro de Oliveira Junior

Doutor em Educação Física

Universidade Estadual de Ponta Grossa - UEPG

Departamento de Educação Física

Ponta Grossa, Paraná, Brasil constantino@uepg.br

(D) https://orcid.org/0000-0003-0577-5262 


\title{
Implementation of public policies: the organization of sport and leisure in the "Programa Novo Mais Educação" (More Education New Program) in the municipal school system of Ponta Grossa - Paraná (2017)
}

\begin{abstract}
This study aims at understanding the organization for the implementation of sport and leisure in the "Programa Novo Mais Educação" (More Education New Program) in the Municipal School System of Ponta Grossa - Paraná (2017). To achieve its aims, Case Study strategies are employed (YIN, 2005) along with Content Analysis (BARDIN, 2011). The data revealed that four schools did not receive the program even if one of them met the selection preferential criteria. The activities of the elective curriculum "Arts and Culture field" were preferred by the school managers when compared to the "Sport and Leisure" activities. The most requested activities were dance, judo and chess. The conclusion was that all schools opted for some Corporal Culture activity.
\end{abstract}

KEYWORDS: Implementation; Public policies; Sport; Leisure

\section{Implementación de políticas públicas: la organización del deporte y ocio en el Programa Novo Mais Educação en la red municipal de educación de Ponta Grossa - Paraná (2017)}

\section{RESUMEN}

El presente estudio tiene por objetivo comprender la organización para la implementación del deporte y ocio en el Programa Novo Mais Educação en la Red Municipal de Educación de Ponta Grossa - Paraná (2017). Para tanto, se utiliza de las estrategias de Estudio de Caso (YIN, 2005) y Análisis de Contenido (BARDIN, 2011). De ese modo, se observa que cuatro escuelas no recibieron el programa, siendo que una de ellas se encajaba en los criterios preferenciales de selección. Las actividades del núcleo optativo del 'Campo de Arte y Cultura' han sido más elegidas por los gestores de las escuelas si comparadas a las de 'Deporte y Ocio'. De entre las actividades más elegidas, se destacan la danza, yudo y ajedrez. Lo que permite concluir que todas las escuelas optaron por alguna actividad da Cultura Corporal.

PALABRAS-CLAVE: Implementación; Políticas públicas; Deporte; Ocio 


\section{INTRODUÇÃO}

A temática de ampliação do tempo de permanência ${ }^{1}$ dos alunos nas escolas públicas no Brasil tem sido cada vez mais frequente no campo acadêmico/científico (CASTANHO; MANCINI, 2016), assim como o aumento de Políticas Públicas ${ }^{2}$ voltadas para essa finalidade (CAVALIERE, 2007). Pode-se encontrar investigações de experiências em nível federal (MAURÍCIO, 2014; BARBOSA; RICHTER; DELGADO, 2015; FLACH, 2015), em nível estadual (CASTRO; LOPES, 2011; SOARES et al., 2014; FEREIRA; REES, 2015; BASEI; BENDRATH; MENEGALDO, 2017), e em nível municipal (COELHO; LOPES, 2014; CARVALHO, 2015; LEITE; RAMALHO, 2015).

Uma das ações em nível federal que visa essa ampliação do tempo de permanência foi o Programa Mais Educação (PME), instituído por meio da Portaria Interministerial $\mathrm{n}^{\circ} 17$ de 24 de abril de 2007, firmada entre os Ministérios da Educação, do Desenvolvimento Social, do Esporte, da Ciência e Tecnologia, da Cultura e do Meio Ambiente, objetivando a implantação da educação integral a partir da reunião dos projetos sociais desenvolvidos pelos Ministérios envolvidos (BRASIL, 2009).

Para Leclerc e Moll (2012) o Programa Mais Educação é uma estratégia indutora para o fortalecimento de uma política de educação integral. Portanto, o Programa Mais Educação é entendido como um modelo para buscar uma melhora na qualidade da educação pública brasileira, usando das ferramentas de aumento do tempo de permanência e a diversificação de atividades em contraturno (SILVA; SILVA, 2013; PENTEADO, 2014; SILVA; SILVA, 2014; BERNADO; CHRISTOVÃO, 2016; SOARES; BRANDOLIN; AMARAL, 2017; ZUCCHETTI; MOURA, 2017).

Por outro lado, Silva e Silva (2013) destacam que o Programa Mais Educação no seu projeto-político pedagógico renova antigas ideias de educação compensatória, com base na equação

\footnotetext{
${ }^{1}$ Para Cavaliere (2007, p.1016) a ampliação do tempo de permanência dos alunos na escola pode ser "entendida e justificada de diferentes formas: (a) ampliação do tempo como forma de se alcançar melhores resultados da ação escolar sobre os indivíduos, devido à maior exposição desses às práticas e rotinas escolares; (b) ampliação do tempo como adequação da escola às novas condições da vida urbana, das famílias e particularmente da mulher; (c) ampliação do tempo como parte integrante da mudança na própria concepção de educação escolar, isto é, no papel da escola na vida e na formação dos indivíduos". Desta forma, entende-se o Programa Novo Mais Educação como uma expressão da forma 'a', visando melhorar os resultados do IDEB das escolas.

${ }^{2}$ Para Souza (2006) não existe uma única, nem melhor, definição sobre o que seja uma política pública. Porém, para este artigo, adota-se a visão da tradição norte-americana, que visa entender, primeiramente, que uma política pública (public policy) se trata de um conjunto de ações implementadas pelos governos, que tem um conteúdo concreto, ou seja, é uma diretriz elaborada para enfrentar um problema público (HOWLETT; RAMESH; PERL, 2013; MARQUES, 2013; SECCHI, 2014, 2016; CHRISPINO, 2016). Assim, os programas e projetos desenvolvidos por um determinado governo são os conteúdos concretos (policy) para o enfrentamento do problema público que eles pretendem resolver.
} 
'proteger e educar', não seguindo a direção de uma educação emancipatória. Apesar disso, entendese que Políticas Públicas com essa finalidade são necessárias. Porém, elas devem ser avaliadas e reformuladas, visando atender as necessidades de uma sociedade e educação do século XXI.

No ano de 2016 o Programa Mais Educação foi reformulado e passou a chamar-se Programa Novo Mais Educação (PNME), que foi instituído pela Portaria ${ }^{\circ}$ 1.144, de 10 de outubro de 2016, do Ministério da Educação (MEC). Assim, o Programa Novo Mais Educação segue o modelo incremental de Políticas Públicas, pois, os problemas e soluções são definidos e revisados ao longo das tomadas de decisões governamentais. Segundo esse modelo grandes saltos ou rupturas de Políticas Públicas são raridades (SECCHI, 2014, 2016).

Dois pontos serviram como justificativa do MEC para a reformulação do seu programa antecessor, o Programa Mais Educação. O primeiro seria o fato do Brasil não ter alcançado a meta estabelecida pelo Índice de Desenvolvimento da Educação Básica (IDEB), para os Anos Finais do Ensino Fundamental e para o Ensino Médio e o segundo seria o desafio de atingir as Metas 6 e 7, do Plano Nacional de Educação, que determinam a ampliação da oferta de educação em tempo integral e a melhoria da qualidade do fluxo escolar e da aprendizagem das escolas públicas, respectivamente (BRASIL, 2016c). Portanto, o Programa Mais Educação sofreu modificações via modelo incremental de Políticas Públicas, resultando no Programa Novo Mais Educação. Dessa forma, reduziram-se as possibilidades de atividades ofertadas no Programa Novo Mais Educação.

Um exemplo desse incrementalismo para área de esporte e lazer foi a desvinculação do Programa Segundo Tempo (PST), do Ministério do Esporte e seus derivantes dentro do Programa Mais Educação. Todavia, o conceito de esporte educacional ${ }^{3}$ é o norteador para as ações do esporte e lazer no Programa Novo Mais Educação. O que caracteriza, conforme Sevegnani (2017), como um conceito central para as Políticas Públicas de Esporte e Lazer (PPEL) e a atuação intersetorial do esporte e lazer.

Com base na noção supracitada de Políticas Públicas, o Programa Novo Mais Educação é uma ação concreta implementada pelo governo federal em colaboração com os governos estaduais e municipais, com o objetivo de enfrentar o problema da qualidade de ensino nos anos iniciais e finais do Ensino Fundamental. Deste modo, o Programa Novo Mais Educação foi estruturado da seguinte forma: o 'núcleo obrigatório' denominado de 'acompanhamento pedagógico' em que o foco é destinado à aprendizagem do aluno em Língua Portuguesa e Matemática e o 'núcleo optativo' denominado de 'atividades complementares', que contempla o campo das 'artes e cultura' e 'esporte e lazer'.

\footnotetext{
${ }^{3}$ Sobre esporte educacional pode-se consultar: TUBINO, Manoel José Gomes. Estudos brasileiros sobre o esporte: Ênfase no esporte-educação. Maringá: Eduem, 2010.
} 
As atividades voltadas a Arte e Cultura são: artesanato, iniciação musical/banda/canto coral, cineclube, dança, desenho, educação patrimonial, escultura/cerâmica, leitura, pintura e teatro/práticas circenses. As voltadas ao Esporte e Lazer: atletismo, badminton, basquete, capoeira, futebol, futsal, ginástica rítmica, handebol, judô, luta olímpica, karatê, natação, taekwondo, tênis de campo, tênis de mesa, voleibol, vôlei de praia e xadrez (BRASIL, 2016c).

Esses objetivos e atividades indicam as diretrizes para o processo de implementação. A implementação é umas das fases do ciclo de políticas públicas, sendo o momento de execução de diretrizes elaboradas anteriormente para a resolução do problema público ${ }^{4}$ alvo da Políticas Públicas (FREY, 2000; SOUZA, 2006; FARIA, 2012; HOWLETT; RAMESH; PERL, 2013; SECCHI, 2014, 2016). Para O’Toole Júnior $(1995 ; 2000 ; 2003)$ a fase de implementação é aquela em que regras e rotinas, são convertidas em ações pelos atores, para lidarem com o problema objeto da política pública.

Para a implementação do Programa Novo Mais Educação em determinada localidade, conforme é indicado pelo documento orientador, passou-se por dois processos de seleção. O primeiro momento foi a adesão das secretarias municipais, estaduais e distrital de educação ao Programa Novo Mais Educação, ocorrida entre 19 de outubro de 2016 a 04 de novembro de 2016. O segundo momento foi a seleção das escolas beneficiadas pelas secretarias contempladas para receber o programa, definidas entre 24 de outubro de 2016 a 18 de novembro de 2016 (BRASIL, 2016c).

Uma das secretarias de educação contempladas para efetivar o processo de implementação foi a Secretaria Municipal de Educação de Ponta Grossa. O município de Ponta Grossa - Paraná possui uma população com cerca de 311 mil pessoas, residindo preponderantemente no meio urbano.

Tendo como foco de estudo o processo de organização para a implementação do Programa Novo Mais Educação e a Rede Municipal de Educação de Ponta Grossa surge, como cenário, a seguinte indagação: como foi organizada a implementação do esporte e lazer no Programa Novo Mais Educação na Rede Municipal de Educação de Ponta Grossa - Paraná? O presente estudo tem por objetivo compreender a organização para a implementação do esporte e lazer no Programa Novo Mais Educação na Rede Municipal de Educação de Ponta Grossa - Paraná, no ano de 2017.

Para concretizar esse objetivo, pretende-se descrever neste artigo os procedimentos metodológicos, apresentar os resultados e discussões - momento em que é apresentada a

\footnotetext{
${ }^{4}$ Para a construção de uma política pública é necessário um problema público, que é entendido quando o status quo é considerado inadequado e existe a expectativa do alcance de uma situação melhor. Portanto, um problema público é compreendido como a diferença entre a situação atual e a situação ideal para a realidade pública (SJÖBLOM, 1984; SECCHI, 2014, 2016).
} 
contextualização da rede municipal de ensino, os critérios para a adesão ao Programa Novo Mais Educação e o esporte e o lazer no Programa Novo Mais Educação na Rede Municipal de Educação de Ponta Grossa. Por fim, apresenta-se nas considerações finais as questões que emergiram dos resultados para possíveis estudos futuros sobre o Programa Novo Mais Educação.

\section{METODOLOGIA}

Este trabalho foi desenvolvido por meio do estudo de caso. Para Yin (2005) o estudo de caso é uma estratégia empregada em pesquisas com questões do tipo 'como' e 'por que', destacando, a identificação de um caso específico ou múltiplo, para a compreensão em profundidade do mesmo. Dessa forma, justifica-se a utilização da estratégia do estudo de caso, visando compreender: 'como' foi organizada a implementação do esporte e lazer no Programa Novo Mais Educação na Rede Municipal de Educação de Ponta Grossa? Desta forma, o caso específico do estudo foi 'a organização para a implementação do esporte e lazer no Programa Novo Mais Educação na Rede Municipal de Educação de Ponta Grossa'.

Para a identificação e aprofundamento do caso recorreu-se aos procedimentos da Análise de Conteúdo de Bardin (2011). A organização da análise ocorreu em três momentos: pré-análise; exploração do material e tratamento dos resultados; e a inferência e interpretação. Na pré-análise foi realizada a leitura flutuante dos seguintes documentos: a) Programa Novo Mais Educação: documento orientador (BRASIL, 2016c); b) Censo escolar (BRASIL, 2015; 2016a); c) Indicadores Educacionais (BRASIL, 2013); d) Índice de Desenvolvimento da Educação Básica (BRASIL, 2016b); e) documentos disponibilizados pela Secretaria Municipal de Educação de Ponta Grossa.

$\mathrm{Na}$ sequência estruturou-se as seguintes categorias para análise do material: a) a rede municipal de ensino; b) critérios para a adesão ao Programa Novo Mais Educação e; c) o esporte e o lazer no Programa Novo Mais Educação na rede municipal de Ponta Grossa. Os dados quantitativos foram tabulados no programa Microsoft Excel.

A partir das categorias elencadas e dos resultados alcançados foi realizada a terceira etapa, inferência e interpretação dos dados, dialogando com os seguintes conceitos: problema público (SJÖBLOM, 1984; SECCHI, 2014, 2016) e de processo de implementação (O'TOOLE JÚNIOR, 1995, 2000, 2003; FREY, 2000; SOUZA, 2006; FARIA, 2012; HOWLETT; RAMESH; PERL, 2013; LIMA; D'ASCENZI, 2013; SECCHI, 2014, 2016). 


\section{RESULTADOS E DISCUSSÃO}

A Rede Municipal de Educação de Ponta Grossa é responsabilidade da Secretaria Municipal de Educação, sendo dividida em Educação Infantil e Ensino Fundamental séries iniciais, contando ao todo, conforme dados do Censo Escolar - Mapa das Escolas de 2016, com 138 escolas sobre a sua administração, sendo 84 Escolas Municipais e 54 Centros de Educação Infantil (BRASIL, 2016a). Destas 84 escolas, 40 são de período integral, 24 estão no processo de implementação gradativa do período integral e 20 escolas estão em período parcial.

Segundo os dados do Censo Escolar de 2015, a Rede Municipal de Educação de Ponta Grossa tinha matriculado 7087 alunos na Educação Infantil e 20699 nos Anos Iniciais do Ensino Fundamental (BRASIL, 2015). Das 84 escolas, de $1^{\circ}$ a $5^{\circ}$ ano do Ensino Fundamental, 80 receberam o Programa Novo Mais Educação.

Nos últimos anos em Ponta Grossa as Políticas Públicas estão buscando o aumento das escolas em tempo integral. Em 2015 foi instituído o Plano Municipal de Educação para o período de 2015 a 2025, Lei Municipal $n^{\circ}$ 12.213/2015, que tem como um dos objetivos o aumento do tempo de permanência das crianças nas escolas da Rede Municipal de Educação de Ponta Grossa. Para alcançar esse objetivo, a Secretaria Municipal de Educação acaba utilizando de políticas públicas em nível federal para facilitar o processo de indução ao aumento do tempo de permanência nas escolas. Exemplos são as adesões ao Programa Mais Educação e ao Programa Novo Mais Educação.

Focando na implementação do Programa Novo Mais Educação no ano de 2017, em Ponta Grossa, destaca-se os 'critérios para a adesão ao Programa Novo Mais Educação's. Neste estudo, buscou-se explicar os motivos da adesão de determinadas escolas ao Programa Novo Mais Educação, segundo o documento orientador do Programa Novo Mais Educação.

As secretarias de educação deveriam selecionar as escolas para participar do programa a partir de três grupos (BRASIL, 2016c). O Grupo 1 refere-se às escolas que receberam recursos na conta do Programa Dinheiro Direto na Escola (PDDE) para a Educação Integral entre 2014 e 2016, recurso repassado através do Fundo Nacional de Desenvolvimento da Educação (FNDE). Na Rede Municipal de Educação de Ponta Grossa, ao todo 18 escolas receberam recursos do FNDE durante os anos de 2014 a 2016. Dessas, 12 escolas receberam recursos durante os três anos consecutivos; cinco escolas receberam esses recursos em 2014 e 2015 e somente uma escola recebeu recursos no ano de 2016. Das 18 escolas que receberam o recurso entre os anos de 2014 e 2016 na Rede

\footnotetext{
${ }^{5}$ Para esse estudo utilizou-se os critérios de adesão dispostos em Brasil (2016c), pois foram os critérios válidos para a implementação no ano de 2017.
} 
Municipal de Educação de Ponta Grossa, todas receberam o Programa Novo Mais Educação. O que ressalta que as escolas integrantes do Grupo 1, foram todas selecionadas para o programa.

O Grupo 2, refere-se às escolas com Índice de Nível Socioeconômico baixo ou muito baixo, e/ou obtiveram desempenho no IDEB inferior à média nacional das escolas públicas e que não se enquadrem no critério do Grupo 1. Na Rede Municipal de Educação de Ponta Grossa, segundo dados do INEP, nenhuma escola está com nível baixo ou muito baixo (BRASIL, 2013). Os dados gerais do IDEB 2015 na tabela 1 permitem analisar a situação da Rede Municipal de Educação de Ponta Grossa.

Tabela 1 - Metas e resultados do IDEB 2015 para as escolas públicas

IDEB 2015

\begin{tabular}{lll}
\hline Brasil & 5.3 & 5.0 \\
Paraná & 6.1 & 5.8 \\
Ponta Grossa & 5.8 & 6.0
\end{tabular}

Fonte: Os autores, elaborado a partir de dados do IDEB (2015).

Quanto ao IDEB, analisando a totalidade da Rede Municipal de Educação de Ponta Grossa, pode-se observar que não atingiu a meta do município, porém há superioridade em relação à média nacional, no entanto, há alguns casos de escolas com média inferior a nacional, conforme se apresenta no Quadro 1.

Quadro 1 - Escolas municipais de Ponta Grossa com IDEB inferior à média nacional das escolas públicas (5.3)

\begin{tabular}{|l|l|l|l|l|l|l|l|}
\hline Escola & A & B & C & D & E & F & G \\
\hline IDEB 2015 & 4.9 & 4.9 & 5.1 & 5.1 & 5.2 & 5.2 & 5.2 \\
\hline $\begin{array}{l}\text { Recebeu o Programa } \\
\text { Novo Mais } \\
\text { Educação? }\end{array}$ & & Sim & Não & Sim & Sim & Sim & Sim \\
\hline
\end{tabular}

Fonte: Os autores, elaborado a partir de dados do IDEB (2015).

Entre as escolas que se enquadram no Grupo 2, apenas a Escola G também apareceu e foi selecionada, através do Grupo 1. Por outro lado, apesar de enquadrar-se no Grupo 2, a Escola C não recebeu o Programa Novo Mais Educação. Considerando que o Programa Novo Mais Educação foi desenvolvido para enfrentar o problema da qualidade de ensino e dos dados apresentados, destacase que a Escola C por enquadrar-se nos critérios de seleção do programa deveria ter recebido o mesmo. 
O Grupo 3 foi caracterizado pelas demais escolas de Ensino Fundamental que não se enquadram nos Grupos 1 e 2, mas puderam aderir ao Programa. Na Rede Municipal de Educação de Ponta Grossa 18 escolas receberam o programa por enquadrarem-se no Grupo 1, cinco pelo Grupo 2, e 57 pelo Grupo 3. O documento orientador indicava que era obrigatório que as Secretarias de Educação indicassem, pelo menos, uma escola nos Grupos 1 e 2 (BRASIL, 2016c). Tal ponto foi cumprido, porém fica a dúvida sobre quais motivos deixaram a Escola $\mathrm{C}$ sem receber o programa, mesmo com o IDEB abaixo da média nacional, sendo que outras 57 escolas que não se encaixavam nem no Grupo 1 e nem no 2, tiveram a oportunidade de participar.

Das 84 escolas da Rede Municipal de Educação de Ponta Grossa quatro delas não receberam o Programa Novo Mais Educação. A seguir apresenta-se no quadro 2 o IDEB das quatro escolas.

Quadro 2 - Resultados e Metas do IDEB 2015 das quatro escolas que não receberam o Programa Novo Mais Educação na Rede Municipal de Educação de Ponta Grossa, comparados à média municipal, estadual e

\begin{tabular}{|l|l|l|l|l|l|}
\hline Escola & IDEB 2015 & $\begin{array}{l}\text { Meta da } \\
\text { Escola 2015 }\end{array}$ & $\begin{array}{l}\text { Média Ponta } \\
\text { Grossa (5.8) }\end{array}$ & $\begin{array}{l}\text { Média Paraná } \\
\mathbf{( 6 . 1 )}\end{array}$ & $\begin{array}{l}\text { Média Brasil } \\
\mathbf{( 5 . 3 )}\end{array}$ \\
\hline C & 5.1 & 5.3 & Inferior & Inferior & Inferior \\
\hline H & 6.5 & 6.2 & Atingiu & Atingiu & Atingiu \\
\hline I & 6.3 & $*$ & Atingiu & Atingiu & Atingiu \\
\hline J & 6.4 & 5.8 & Atingiu & Atingiu & Atingiu \\
\hline
\end{tabular}

Fonte: Os autores, elaborado a partir de dados do IDEB (2015).

A Escola C, não atingiu nem mesmo a meta interna, além disso, é uma das escolas com maior número de alunos na Rede Municipal de Educação de Ponta Grossa, atende 868 alunos, o que demonstra que podem haver muitos alunos com problemas na qualidade de ensino, reforçando ainda mais a necessidade do Programa Novo Mais Educação na escola.

Após a Rede Municipal de Educação de Ponta Grossa optar pelas escolas que receberiam o Programa Novo Mais Educação, a equipe gestora de cada uma das escolas ficou responsável por selecionar as atividades. O Programa Novo Mais Educação é composto por acompanhamento pedagógico obrigatório, em língua portuguesa e matemática, e atividades complementares que estão vinculadas ao campo das Artes e Cultura ou do Esporte e Lazer.

Conforme supracitado na Rede Municipal de Educação de Ponta Grossa, 80 escolas receberam o Programa Novo Mais Educação e cada uma pôde escolher três atividades complementares, totalizando 240 atividades, sendo 138 (57,5\%) de Artes e Cultura e 102 (42,5\%) de Esporte e Lazer. Dessas, 69 escolas optaram por ambos os campos, sete apenas pelas Artes e 
Cultura e duas apenas pelo Esporte e Lazer. Basei, Bendrath e Menegaldo (2017) ao analisarem as atividades complementares de contraturno escolar na rede estadual do Paraná, destacaram que entre nove macrocampos, 35,4\% das atividades complementares no Estado são de Esporte e Lazer, sendo uma das opções mais escolhidas pelos gestores escolares, bem como, as atividades de aprofundamento de aprendizagem.

Na cidade de Ponta Grossa, Sousa (2015) destaca que a Rede Municipal de Educação de Ponta Grossa recebeu pela primeira vez o Programa Mais Educação, especialmente o macrocampo Programa Segundo Tempo (PST) no ano de 2013, por meio de três escolas. Pode-se inferir que no modelo Programa Novo Mais Educação aconteceu uma maior adesão da Secretaria Municipal de Educação a programas voltados para a expansão do tempo de permanência nas escolas.

Das sete escolas que optaram exclusivamente por atividades de Artes e Cultura, todas escolheram entre as atividades a dança, o que demonstra que em todas as escolas da rede municipal os temas da Cultura Corporal $^{6}$ estão presentes.

A dança enquanto parte de um processo educacional é objeto de disputa entre a Educação Física e a Arte, seja em espaço curricular ou não (GARIBA; FRANZONI, 2007; BRASILEIRO, 2012). O exemplo dessa tensão está na alocação da dança dentro do Programa Novo Mais Educação. Por mais que a dança possa ser entendida com um elemento da Cultura Corporal, no Programa Novo Mais Educação fica restrita a área de Artes. Ou seja, diante do objeto em disputa pela legitimidade do ensino, a educação física perdeu espaço não tendo a possibilidade de ofertar a dança como atividade complementar vinculada ao esporte e lazer. Com isso, limitando um possível campo de atuação para profisssionais formados e em formação.

A seguir, apresenta-se no Gráfico 1, as atividades relacionadas a Esporte e Lazer, desenvolvidas por meio do Programa Novo Mais Educação na Rede Municipal de Educação de Ponta Grossa.

\footnotetext{
${ }^{6}$ Por Cultura Corporal entende-se, conforme Soares et al. (1992), como temas ou forma de atividades, particularmente corporais, sendo elas as danças, esporte, ginástica, jogos e lutas, empregando sentidos e significados onde se interpenetram, dialeticamente, a intencionalidade/objetivos do homem e as intenções/objetivos da sociedade. É necessário ponderar que não é possível saber até que ponto, as atividades desenvolvidas no programa estão alinhadas aos pressupostos teórico-metodológico de Soares et al (1992). Porém, apropriamos desse conceito como divisão de conteúdos corporais, para questão de categorização e organização dos dados.
} 
Gráfico 1 - Atividades de Esporte e Lazer e o número de escolas municipais de Ponta Grossa, que as desenvolvem por meio do Programa Novo Mais Educação

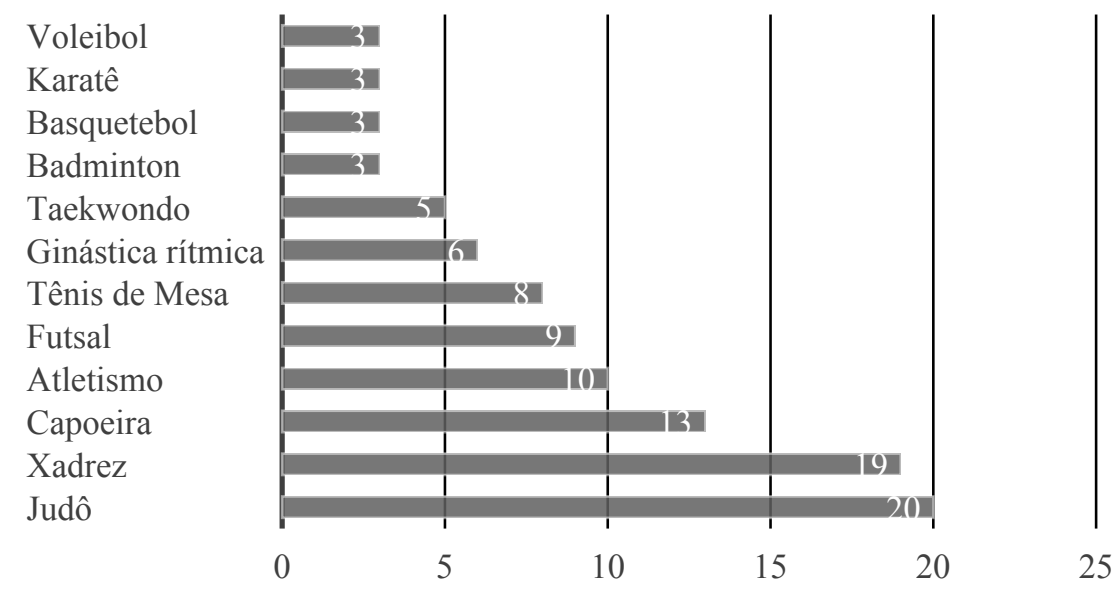

Fonte: Os autores.

Conforme pode ser observado no Gráfico 1, o judô foi a atividade mais escolhida pelas escolas, seguido de xadrez e capoeira. Juntas as três atividades somam mais de $50 \%$ das escolhidas. Modalidades estas que não são consideradas tradicionais na temática da Cultura Corporal. Resultado diferente do encontrado por Meireles et al (2016) e Basei, Brendath e Menegaldo (2017), que identificaram a predominância de esportes como: atletismo, futebol, futsal e voleibol.

Infere-se que essas escolhas foram dominantes devido ao imaginário social ligado às lutas como possível atividade para disciplinar o corpo, assim como ensinar o respeito para os alunos. Em relação ao xadrez, devido há sua possível contribuição no desenvolvimento do raciocínio lógicomatemático e pela Lei Municipal n. ${ }^{\circ}$ 11.910/2014, que visa à obrigatoriedade do xadrez nas escolas da Rede Municipal de Educação de Ponta Grossa.

Não foram escolhidas pelas escolas da Rede Municipal de Educação de Ponta Grossa as seguintes atividades: futebol, handebol, luta olímpica, natação, tênis de campo e vôlei de praia. Infere-se que os motivos para a não escolha dessas atividades podem estar relacionados à dificuldade estrutural no caso do futebol, natação, tênis de campo e vôlei de praia. É com certa estranheza que o handebol não foi selecionado, por ser, conforme Betti (1999), um dos temas da cultura corporal predominante nas escolas, ao lado de basquete, futsal e vôlei.

Apresenta-se no Gráfico 2 as atividades do campo de Artes e Cultura desenvolvidas através do Programa Novo Mais Educação na Rede Municipal de Educação de Ponta Grossa. 
Gráfico 2 - Atividades do campo de Artes e Cultura, e o número de escolas municipais de Ponta Grossa, que as desenvolvem por meio do Programa Novo Mais Educação.

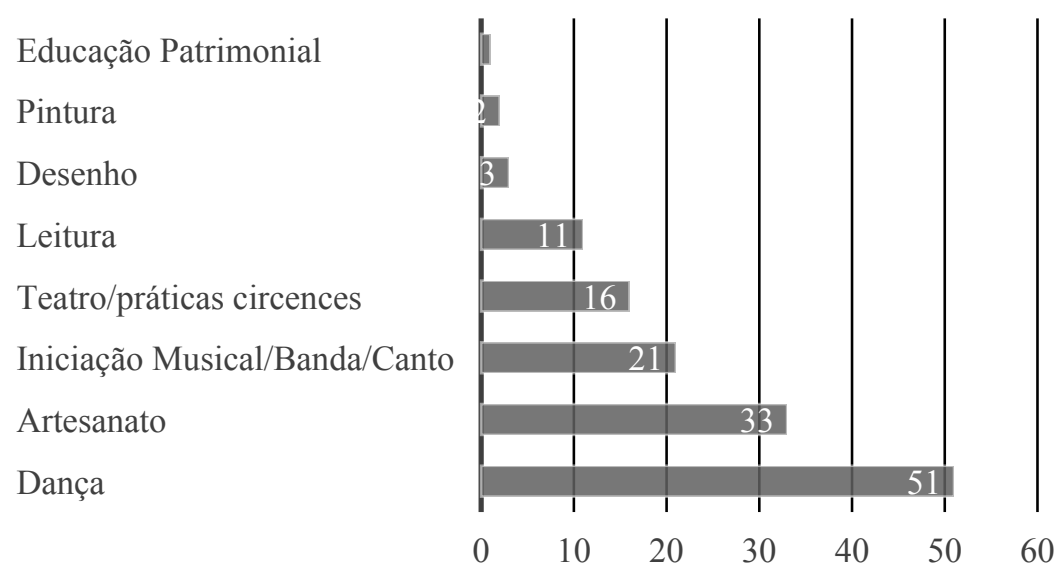

Fonte: Os autores.

Observa-se no Gráfico 2, que dentre as 138 atividades da área de Artes e Cultura, a dança foi escolhida 51 vezes, seguida de artesanato e iniciação musical/banda/canto. Destaca-se que a dança é um dos temas da Cultura Corporal. No estudo de Basei, Brendath e Menegaldo (2017) a atividade complementar de dança foi analisado juntamente com o macrocampo esporte e lazer.

Entre as 240 atividades escolhidas pelas escolas da Rede Municipal de Educação de Ponta Grossa, 153 (63,7\%), abordam temas da Cultura Corporal, o que demonstra que a temática além de estar presente em todas as escolas é predominante também em termos quantitativos. A seguir, apresentam-se os componentes da cultura corporal em que se evidenciam o esporte, a dança e as lutas como atividades de maior escolha, em detrimento da ginástica.

Gráfico 3 - Componentes da Cultura Corporal e o número de escolas municipais de Ponta Grossa que os desenvolvem no Programa Novo Mais Educação.

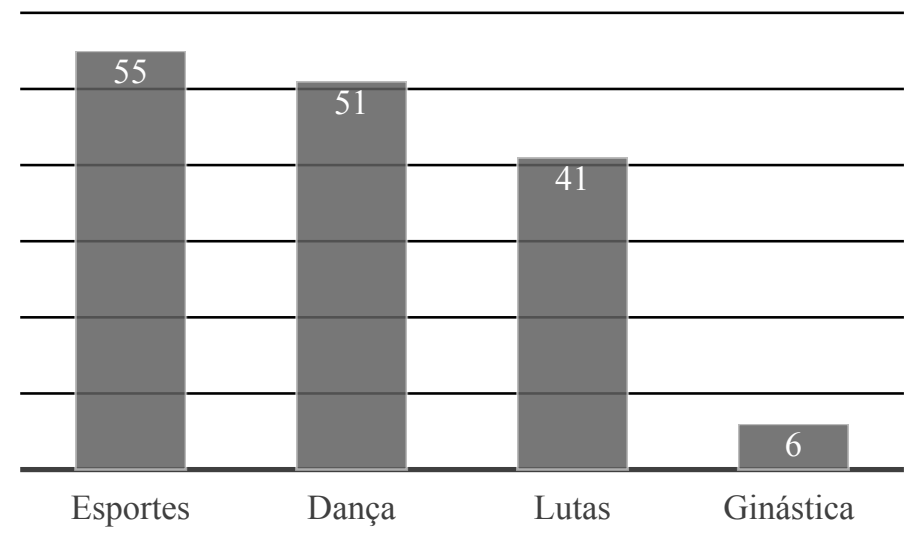

Fonte: Os autores. 
Essa grande presença de temas da cultura corporal nas escolas da Rede Municipal de Educação de Ponta Grossa que receberam o Programa Novo Mais Educação pode ser explorada por profissionais da área de educação física para entrar em um campo de atuação que não é novo, a escola, porém com uma particular diferença das aulas de educação física, ou seja, o esporte e o lazer em espaço de contraturno escolar visando à ampliação da carga horária dos alunos nas escolas.

Contudo, como esse espaço deve ser ocupado e como deve ser a ação do profissional nesse momento, o documento orientador do Programa Novo Mais Educação não deixa claro. Entretanto, pode ser uma lacuna que estudiosos do tema políticas públicas de esporte e lazer devem explorar emergencialmente. Como devem ser as atividades de esporte e lazer em políticas públicas voltadas para um fim que não é o próprio esporte e o lazer, mas sim um meio para melhorar os índices avaliativos do governo federal?

Outro ponto preocupante é que em nenhum momento do documento orientador é citado que para trabalhar com as atividades complementares de esporte e lazer dentro do Programa Novo Mais Educação é preciso ser um profissional da área de educação física ou estar cursando a graduação (BRASIL, 2016c). Essa questão é muito mais problemática do que a primeira, 'trafegando' na contramão de toda a formação de pessoas aptas para atuar no esporte e no lazer no Brasil, situação que precisa da atenção do campo acadêmico/científico da área.

\section{CONSIDERAÇÕES FINAIS}

Esta pesquisa visou compreender a organização para a implementação do esporte e lazer no Programa Novo Mais Educação na Rede Municipal de Educação de Ponta Grossa, em 2017, e chegou às seguintes considerações sobre o caso.

Ponta Grossa superou a meta nacional do IDEB para escolas públicas, porém não atingiu a meta interna para o município. Assim, o Programa Novo Mais Educação, além de contribuir para a busca de um ensino de qualidade, pode ser também uma importante ferramenta para auxiliar a Rede Municipal de Educação de Ponta Grossa no processo de implementação da ampliação do tempo de permanência, atingindo assim um dos objetivos do Programa Novo Mais Educação e do Plano Nacional de Educação.

Em relação ao esporte e lazer como 'atividades complementares' ao núcleo obrigatório do Programa Novo Mais Educação, as atividades de judô e xadrez foram as que tiveram a maior adesão por parte da gestão escolar. É possível inferir que essas escolhas foram dominantes devido ao imaginário social ligado às lutas como possível atividade para disciplinar o corpo e ensino de 
valores morais. E o xadrez foi selecionado por sua possível contribuição no desenvolvimento do raciocínio lógico-matemático e da influência da legislação municipal.

Outro fato que merece destaque é o caso da dança, atividade da Cultura Corporal que no Programa Novo Mais Educação foi atribuída ao campo da arte. Somados os temas ligados a Cultura Corporal presentes nas escolas da Rede Municipal de Educação de Ponta Grossa que receberam o Programa Novo Mais Educação, pode-se afirmar que estão presentes em todas as escolas com a função de aumentar o tempo de crianças e adolescentes dentro da escola.

O foco do presente trabalho foi a organização do processo de implementação do esporte e lazer no Programa Novo Mais Educação na Rede Municipal de Educação de Ponta Grossa. A partir do estudo de caso da Rede Municipal de Educação de Ponta Grossa, emergiu a necessidade de um novo estudo de caso, focado na Escola C. Pois, mesmo estando enquadrada conforme os critérios do Grupo 2, para a adesão ao programa, foi a única escola com nota abaixo da média nacional do IDEB na Rede Municipal de Educação de Ponta Grossa a não receber o Programa Novo Mais Educação. Deste modo, identifica-se um afastamento entre os objetivos do Programa Novo Mais Educação e a execução local.

Por fim, por meio desta pesquisa foi possível vislumbrar três possibilidades de aprofundamento: quais os motivos que levaram a Secretaria Municipal de Educação a não escolher a Escola C para ofertar o Programa Novo Mais Educação? Quais os motivos que levaram às equipes gestoras optarem por atividades com xadrez ou judô, ao invés dos esportes tradicionais? E o porquê da não inclusão da dança como componente do esporte e lazer dentro do Programa Novo Mais Educação?

Pode-se evidenciar questões secundárias emergidas deste estudo para novos trabalhos: como a área de educação física está pensando a ampliação do tempo de permanência nas escolas? Como estamos pensando o papel do esporte, lazer e dos temas da Cultura Corporal nessa nova configuração dentro da escola? Essa discussão da ampliação do tempo de permanência na escola tem sido contemplada no campo acadêmico/científico da educação física? Quem está trabalhando nesse contexto recebeu formação adequada para essa nova realidade? Como estão acontecendo essas atividades no cotidiano escolar? Como os profissionais estão elaborando as suas atividades? Para responder essas questões, é preciso mergulhar no cotidiano das escolas que receberam e receberão o Programa Novo Mais Educação, para assim conseguir revelar a realidade do processo de implementação do Programa Novo Mais Educação. Isso só será possível se houver o diálogo do campo da Educação Física com as teorias de implementação de Políticas Públicas como o top-down ou bottom-up apontados por Howlett; Ramesh; Perl, (2013), por Lima; D’Ascenzi (2013) e por Secchi (2014 e 2016), foco não condizente com o atual trabalho, já que a lente de análise foi 
compreender a organização antes do processo de implementação ganhar vida. Porém, as preguntas lançadas para o campo acadêmico/científico são fundamentais para o amadurecimento do estudo sobre Políticas Públicas de Esporte e Lazer. Portanto, esse será um desafio futuro, o qual os autores deste trabalho estarão incumbidos.

\section{REFERÊNCIAS}

BARBOSA, Maria Carmen Silveira; RICHTER, Sandra Regina Simonis; DELGADO, Ana Cristina Coll. Educação Infantil: tempo integral ou educação integral? Educação em Revista, Belo Horizonte, v. 31, n. 4, p.95-119, out./dez. 2015. Disponível em: $<$ http://www.scielo.br/scielo.php?script=sci_arttext\&pid=S010246982015000400095\&lng=en\&nrm=iso $>$. Acesso em: 26 abr. 2017

BARBOSA, Maria Carmen Silveira; RICHTER, Sandra Regina Simonis; DELGADO, Ana Cristina Coll. EDUCAÇÃO INFANTIL: TEMPO INTEGRAL OU EDUCAÇÃO INTEGRAL?. Educação em Revista, Belo Horizonte, v. 31, n. 4, p.95-119, dez. 2015. Disponível em: http://dx.doi.org/10.1590/0102-4698151363. Acesso em: 26 abr. 2017.

BARDIN, Laurence. Análise de conteúdo. São Paulo: Edições 70, 2011.

BASEI, Andréia Paula; BENDRATH, Eduard Angelo; MENEGALDO, Pedro Henrique Iglesiaz. Atividades complementares curriculares em contraturno escolar no estado do Paraná: um estudo do macrocampo esporte e lazer. Motrivivência, Florianópolis, v. 29, n. 51, p. 136-156, julho, 2017. Disponível em: https://periodicos.ufsc.br/index.php/motrivivencia/article/view/21758042.2017v29n51p136. Acesso em: 20 abr. 2018.

BERNADO, Elisangela da Silva; CHRISTOVAO, Ana Carolina. Tempo de Escola e Gestão Democrática: o Programa Mais Educação e o IDEB em busca da qualidade da educação. Educação \& Realidade, Porto Alegre, v. 41, n. 4, p. 1113-1140, out./dez. 2015. Disponível em: http://www.scielo.br/scielo.php?script=sci_arttext\&pid=S217562362016000401113\&lng=en\&nrm=iso. Acesso em: 26 abr. 2017

BETTI, Irene Conceição Rangel. Esporte na escola: mas é só isso, professor? Revista Motriz, Rio Claro, v. 1, n. 1, p. 25-31, jun. 1999. Disponível em: https://fefd.ufg.br/up/73/o/Texto_105_Esporte_na_escola_Mas______ isso_professor__Irene_Concei___ o_Rangel_Betti.pdf. Acesso em: 25 abr. 2017.

BRASIL. Portaria Interministerial no 17, de 24 de abril de 2007. Institui o Programa Mais Educação, que visa fomentar a educação integral de crianças, adolescentes e jovens, por meio do apoio a atividades sócio-educativas no contraturno escolar. Disponível em: http://www.abmes.org.br/abmes/public/arquivos/legislacoes/Port Norm Inter 017200704 24.pd f. Acesso em: 05 de março de 2018.

BRASIL. Ministério da Educação. Pressupostos para projetos pedagógicos de educação integral: caderno para professores e diretores de escolas. Brasília, 2009. Disponível em: http://portal.mec.gov.br/dmdocuments/cad mais educacao.pdf. Acesso em: 20 de outubro de 2017. 
BRASIL. Ministério da Educação. Instituto Nacional de Estudos e Pesquisas Educacionais. Instituto Nacional de Estudos e Pesquisas Educacionais. Censo Escolar - mapa das escolas. Brasília, 2016a. Disponível em: http://inepdata.inep.gov.br/analytics/saw.dll?Dashboard. Acesso em: 05 abr. 2017.

BRASIL. Ministério da Educação. Instituto Nacional de Estudos e Pesquisas Educacionais.

Indicadores Educacionais. Brasília, 2013. Disponível em: http://portal.inep.gov.br/indicadoreseducacionais. Acesso em: 22 abr. 2017.

BRASIL. Ministério da Educação. Instituto Nacional de Estudos e Pesquisas Educacionais. Índice de Desenvolvimento da Educação Básica. Brasília, 2016b. Disponível em: http://ideb.inep.gov.br/. Acesso em: 22 abr. 2017.

BRASIL. Ministério da Educação. Instituto Nacional de Estudos e Pesquisas Educacionais. Resultados Finais do Censo Escolar 2015. Brasília, 2015. Disponível em: http://matricula.educacenso.inep.gov.br/controller.php. Acesso em: 22 abr. 2017.

BRASIL. Ministério da Educação. Secretaria de Educação Básica. Programa Novo Mais Educação. Brasília, 2016c. Disponível em: http://portal.mec.gov.br/index.php?option=com_docman\&view=download\&alias=53061-novomais-educacao-documento-orientador-pdf\&category_slug=dezembro-2016-pdf\&Itemid=30192. Acesso em: 05 abr. 2017.

BRASILEIRO, Lívia Tenorio. DANÇA: SENTIDO ESTÉTICO EM DISCUSSÃO. Movimento (ESEFID/UFRGS), Porto Alegre, p. 189-203, abr. 2012. ISSN 1982-8918. Disponível em: http://www.seer.ufrgs.br/index.php/Movimento/article/view/19195. Acesso em: 14 jun. 2017.

CARVALHO, Levindo Diniz. Crianças e infâncias na educação (em tempo) integral. Educação em Revista, Belo Horizonte, v. 31, n. 4, p.23-43, jul. 2015. Disponível em: http://www.scielo.br/pdf/edur/2015nahead/0102-4698-edur-136686.pdf. Acesso em: 25 abr. 2017.

CASTANHO, Marisa Irene Siqueira; MANCINI, Silvana Gomes. Educação Integral no Brasil: potencialidades e limites em produções acadêmicas sobre análise de experiências. Ensaio:

Avaliação e Políticas Públicas em Educação, Rio de Janeiro, v. 24, n. 90, p. 225-248, jan./mar. 2016. Disponível em: http://www.scielo.br/scielo.php?script=sci arttext\&pid=S0104$40362016000100225 \& \operatorname{lng}=$ en\&nrm=iso. Acesso em: 25 abr. 2017.

CASTRO, Adriana de; LOPES, Roseli Esquerdo. A escola de tempo integral: desafios e possibilidades. Ensaio: Avaliação e Políticas Públicas em Educação, Rio de Janeiro, v. 19, n. 71, p. 259-282, jun. 2011. Disponível em:

http://www.scielo.br/scielo.php?script=sci_arttext\&pid=S0104$40362011000300003 \& 1 n g=e n \& n r m=$ iso. Acesso em: 25 abr. 2017.

CAVALIERE, Ana Maria. Tempo de escola e qualidade na educação pública. Educação \& Sociedade, Campinas, v. 28, n. 100, p. 1015-1035, out. 2007. Disponível em: http://www.scielo.br/scielo.php?script=sci_arttext\&pid=S0101$73302007000300018 \& \operatorname{lng}=$ en\&nrm=iso. Acesso em: 25 abr. 2017.

CHRISPINO, A. Introdução ao estudo de Políticas Públicas: uma visão interdisciplinar e contextualizada. Rio de Janeiro: FGV Editora, 2016. 
COELHO, Lígia Martha Coimbra da Costa; MARQUES, Luciana Pacheco; BRANCO, Verônica. Políticas públicas municipais de educação integral e (m) tempo ampliado: quando a escola faz a diferença. Ensaio: Avaliação e Políticas Públicas em Educação, Rio de Janeiro, v. 22, n. 83, p. 355-378, jun. 2014. Disponível em:

http://www.scielo.br/scielo.php?script=sci_arttext\&pid=S0104-

$40362014000200005 \& \operatorname{lng}=$ en\&nrm=iso. Acesso em: 25 abr. 2017.

FARIA, Carlos Aurélio Pimenta de. (Org.) Implementação de políticas públicas: teoria e prática. Belo Horizonte: Ed. PUC Minas, 2012.

FERREIRA, Helen Betane; REES, Dilys Karen. Educação Integral e Escola de Tempo Integral em Goiânia. Educação \& Realidade, Porto Alegre, v. 40, n. 1, p. 229-251, jan./mar. 2015. Disponível em: http://www.scielo.br/scielo.php?script=sci_arttext\&pid=S2175-

62362015000100229\&lng=en\&nrm=iso. Acesso em: 25 abr. 2017.

FLACH, Simone de Fátima. Ensino fundamental no Brasil: previsões legais e ações governamentais para a ampliação do atendimento, da duração e do tempo escolar. Ensaio: Avaliação e Políticas Públicas em Educação, Rio de Janeiro, v. 23, n. 88, p. 739-762, set. 2015. Disponível em: http://www.scielo.br/scielo.php?script=sci_arttext\&pid=S0104$40362015000300739 \& \operatorname{lng}=$ en\&nrm=iso. Acesso em: 25 abr. 2017.

FREY, Klaus. Políticas Públicas: um debate conceitual e reflexões referentes à prática de análise de políticas públicas no Brasil. Planejamento e Políticas Públicas, Brasília, n.21, jun. 2000. Disponível em: http://www.ufpa.br/epdir/images/docs/paper21.pdf. Acesso em: 10 abr. 2017.

GARIBA, Chames Maria Stalliviere; FRANZONI, Ana. Dança escolar: uma possibilidade na Educação Física. Movimento (ESEFID/UFRGS), Porto Alegre, v. 13, n. 2, p. 155-171, abr. 2008. ISSN 1982-8918. Disponível em:

http://www.seer.ufrgs.br/index.php/Movimento/article/view/3553. Acesso em: 14 jun. 2017.

GIL, Antônio Carlos. Métodos e técnicas de pesquisa social. 6. ed. São Paulo: Atlas, 2008.

HOWLETT, Michael; RAMESH, M.; PERL, Anthony. Política pública: seus ciclos e subsistemas. Uma abordagem integral. Rio de Janeiro: Elsevier, 2013.

INSTITUTO BRASILEIRO DE GEOGRAFIA E ESTATÍSTICA - IBGE. Produto Interno Bruto dos Municípios. Disponível em:

http://www.ibge.gov.br/home/estatistica/economia/pibmunicipios/2014/default.shtm. Acesso em: 23 abr. 2017.

LECLERC, Gesuína de Fátima Elias; MOLL, Jaqueline. Programa Mais Educação: avanços e desafios para uma estratégia indutora da Educação Integral e em tempo integral. Educar em Revista, Curitiba, n. 45, p. 91-110, jul./set. 2012. Disponível em: http://www.scielo.br/pdf/er/n45/07.pdf. Acesso em: 12 abr. 2017.

LEITE, Lúcia Helena Alvarez; RAMALHO, Bárbara. Jovens-adolescentes egressos de uma educação integral: a construção de atitudes e valores. Educação em Revista, Belo Horizonte, v. 31, n. 4, p. 63-80, out./dez. 2015. Disponível em: 
http://www.scielo.br/scielo.php?script=sci_arttext\&pid=S0102-

$46982015000400063 \& \operatorname{lng}=$ en\&nrm=iso. Acesso em: 25 abr. 2017.

LIMA, Luciana Leite; D'ASCENZI, Luciano. Implementação de políticas públicas: perspectivas analíticas. Rev. Sociol. Polit., Curitiba, v. 21, n. 48, p. 101-110, Dez. 2013. Disponível em: http://www.scielo.br/scielo.php?script=sci_arttext\&pid=S0104$44782013000400006 \& \operatorname{lng}=$ en\&nrm=iso. Acesso em: 10 out. 2018.

MARQUES, Eduardo. As políticas públicas na Ciência Política. In: MARQUES, Eduardo; FARIA, Carlos Aurélio Pimenta de. (Org.) Apolítica pública como campo multidisciplinar. São Paulo: Editora Unesp, 2013.

MAURICIO, Lúcia Velloso. Ampliação da jornada escolar: configurações próprias para diferentes contextos - Brasil e Europa. Ensaio: Avaliação e Políticas Públicas em Educação, Rio de Janeiro, v. 22, n. 85 , p. 875-898, out./dez. 2014.Disponível em:

http://www.scielo.br/scielo.php?script=sci_arttext\&pid=S0104-

$40362014000400002 \& 1 n g=e n \& n r m=$ iso. Acesso em: 25 abr. 2017.

MINAYO, Maria Cecília de Souza. O desafio da pesquisa Social. In: MINAYO, Maria Cecília de Souza. (Org.) Pesquisa Social: teoria, método e criatividade. 31. ed. Petrópolis: Vozes, 2012.

O'TOOLE JR., Laurence J. Interorganizational relations in implementation. In: PETERS, B. G.; PIERRE, J. (Orgs.) Handbook of public administration. Londres: Thousand Oaks/Sage Publications, 2003.

O'TOOLE JR., Laurence J. Research on policy implementation: assessment and prospects. Journal of Public Administration Research and Theory, v. 10, n. 2, p. 263-288, abr. 2000. Disponível em: http://doc.utwente.nl/1400/1/J\%20Public\%20Adm\%20Res\%20Theory-2000-O\%27Toole-26388.pdf. Acesso em: 15 abr. 2017.

O'TOOLE JR., Laurence J. Rational choice and policy implementation: implications for interorganizational network management. American Review of Public Administration, v.25, n. 1, p.43-57, 1995. Disponível em: http://journals.sagepub.com/doi/pdf/10.1177/027507409502500103. Acesso em: 15 abr. 2017.

PENTEADO, Andrea. Programa Mais Educação como Política de Educação Integral para a Qualidade. Educação \& Realidade, Porto Alegre, v. 39, n. 2, p. 463-486, abr./jun. 2014.

Disponível em: http://seer.ufrgs.br/index.php/educacaoerealidade/article/view/41472. Acesso em: 25 abr. 2017.

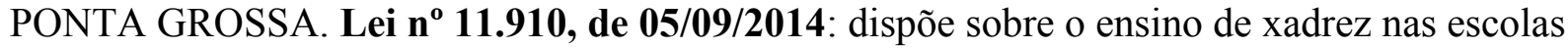
públicas municipais. 2014. Disponível em: <http://sme.pontagrossa.pr.gov.br/lei.pdf $>$. Acesso em: 20 abr. 2018.

PONTA GROSSA. Lei n⿳ 12.213, de 23/06/2015: Institui o Plano Municipal de Educação para o período de 2015 a 2025. 2015. Disponível em: https://leismunicipais.com.br/a1/pr/p/pontagrossa/lei-ordinaria/2015/1222/12213/lei-ordinaria-n-12213-2015-institui-o-plano-municipal-deeducacao-para-o-periodo-de-2015-a-2025. Acesso em: 20 abr. 2018. 
PROGRAMA DAS NAÇÕES UNIDAS PARA O DESENVOLVIMENTO - PNUD. Atlas do

Desenvolvimento Humano no Brasil. Disponível em:

http://www.atlasbrasil.org.br/2013/pt/consulta/. Acesso em: 23 abr. 2017.

SECCHI, Leonardo. Análise de Políticas Públicas: diagnóstico de problemas, recomendação de soluções. São Paulo: Cengage Learning, 2016.

SECCHI, Leonardo. Políticas públicas: conceitos, esquemas de análise, casos práticos. São Paulo: Cengage Learning, 2014.

SEVEGNANI, Palmira. O esporte educacional no Sistema Nacional: a intersetorialidade na política pública de esporte, 2017, 247 f. Tese (Doutorado em Educação Física) - Universidade Federal do Paraná, Curitiba, 2017. Disponível em:

https://acervodigital.ufpr.br/bitstream/handle/1884/47789/R\%20-\%20T\%20-

\%20\%20PALMIRA\%20SEVEGNANI.pdf?sequence=1\&isAllowed=y. Acesso em: 20 abr. 2018.

SILVA, Jamerson Antônio de Almeida da; SILVA, Katharine Ninive Pinto. A hegemonia às avessas no Programa Mais Educação. Revista Brasileira de Estudos Pedagógicos, Brasília, v. 94, n. 238, p. 701-720, set./dez. 2013. Disponível em:

http://rbep.inep.gov.br/index.php/rbep/article/view/355. Acesso em: 25 maio 2017.

SILVA, Jamerson Antônio de Almeida da; SILVA, Katharine Ninive Pinto. Analisando a concepção de Educação Integral do governo Lula/Dilma através do Programa Mais

Educação. Educação em Revista, Belo Horizonte, v. 30, n. 1, p. 95-126, jan./mar. 2014.

Disponível em: http://www.scielo.br/scielo.php?script=sci_arttext\&pid=S0102-

$46982014000100005 \& \operatorname{lng}=$ en\&nrm=iso. Acesso em: 25 abr. 2017.

SJOBLOM, Gunnar. Problemi e soluzioni in politica. Rivista Italiana di Scienza Politica, v. 14, n. 1, p.41-85, 1984.

SOARES, Antônio Jorge Gonçalves; BRANDOLIN, Fabio; AMARAL, Daniela Patti do. Desafios e Dificuldades na Implementação do Programa Mais Educação: percepção dos atores das escolas.

Educação \& Realidade, Porto Alegre, mar. 2017. Disponível em:

http://www.scielo.br/scielo.php?script=sci_arttext\&pid=S2175-

62362017005002103\&lng=en\&nrm=iso. Acesso em: 25 maio 2017.

SOARES, Carmen Lúcia et al. Metodologia do Ensino de Educação Física. São Paulo: Cortez, 1992.

SOARES, Tufi Machado et al. Escola de Tempo Integral: resultados do projeto na proficiência dos alunos do Ensino Fundamental das escolas públicas da rede estadual de Minas Gerais. Ensaio:

Avaliação e Políticas Públicas em Educação, Rio de Janeiro, v. 22, n. 82, p. 111-130, jan./mar.

2014. Disponível em: http://www.scielo.br/scielo.php?script=sci_arttext\&pid=S0104-

$40362014000100006 \& \operatorname{lng}=$ en\&nrm=iso. Acesso em: 25 abr. 2017.

SOUSA, Diego Petyk. O Programa Segundo Tempo no Mais Educação entre documentos e discursos: os casos dos profissionais de Ponta Grossa - Paraná. 2015, 129 f. Dissertação (Mestrado em Ciências Sociais Aplicadas) - Universidade Estadual de Ponta Grossa, Ponta Grossa, 2015. Disponível em: http://bicen-tede.uepg.br/tde_busca/arquivo.php?codArquivo=1445. Acesso em: 10 abr. 2017. 
SOUZA, Celina. Políticas Públicas: uma revisão da literatura. Sociologias, Porto Alegre, v.8, n.16, jul./dez. 2006, p.20-45. Disponível em: http://www.scielo.br/pdf/soc/n16/a03n16. Acesso em: 10 abr. 2017.

YIN, Robert K. Estudo de caso: Planejamento e métodos. Porto Alegre: Bookman, 2005.

ZUCCHETTI, Dinora Tereza; MOURA, Eliana Perez Gonçalves de. Educação integral. Uma questão de direitos humanos? Ensaio: Avaliação e Políticas Públicas em Educação, Rio de Janeiro, v. 25, n. 94, p. 257-276, jan./mar. 2017. Disponível em: http://www.scielo.br/scielo.php?script=sci_arttext\&pid=S0104$40362017000100257 \& 1 n g=e n \& n r m=$ iso. Acesso em: 25 maio 2017.

\section{NOTAS DE AUTOR}

\section{AGRADECIMENTOS}

Agradecemos o apoio da Coordenação de Aperfeiçoamento de Pessoal de Nível Superior - Brasil (CAPES) pelas bolsas de mestrado (Érica) e doutorado (Diego), ao Instituto Federal do Paraná pela a liberação para capacitação (Mariana), ao Programa de Pós-Graduação em Ciências Sociais Aplicadas da Universidade Estadual de Ponta Grossa (UEPG), aos membros do Grupo de Estudos Esporte, Lazer e Sociedade (UEPG), a Secretaria Municipal de Educação de Ponta Grossa e a própria Universidade Estadual de Ponta Grossa pelo o incentivo no desenvolvimento de pesquisas.

\section{CONTRIBUIÇÃO DE AUTORIA}

Os papéis descrevem a contribuição específica de cada colaborador para a produção acadêmica inserir os dados dos autores conforme exemplo, excluindo o que não for aplicável. Iniciais dos primeiros nomes acrescidas com o último Sobrenome, conforme exemplo.

Concepção do manuscrito: L. S. Sobrenome, J. T. Sobrenome, A. P. Sobrenome

Coleta de dados: L. S. Sobrenome, J. T. Sobrenome, A. P. Sobrenome

Análise de dados: L. S. Sobrenome, J. T. Sobrenome

Discussão dos resultados: J. T. Sobrenome

Produção do texto: L. S. Sobrenome, J. T. Sobrenome, A. P. Sobrenome

Revisão e aprovação: A. P. Sobrenome

Caso necessário veja outros papéis em: https://casrai.org/credit/

\section{FINANCIAMENTO}

O presente trabalho foi realizado com apoio da Coordenação de Aperfeiçoamento de Pessoal de Nível Superior - Brasil (CAPES) - Código de Financiamento 001.

\section{CONSENTIMENTO DE USO DE IMAGEM}

Não se aplica. 


\section{APROVAÇÃO DE COMITÊ DE ÉTICA EM PESQUISA}

Não se aplica.

\section{CONFLITO DE INTERESSES}

Não temos nenhum conflito de interesses

\section{LICENÇA DE USO}

Os autores cedem à Motrivivência - ISSN 2175-8042 os direitos exclusivos de primeira publicação, com o trabalho simultaneamente licenciado sob a Licença Creative Commons Attribution Non-Comercial ShareAlike (CC BY-NC SA) 4.0 International. Estra licença permite que terceiros remixem, adaptem e criem a partir do trabalho publicado, desde que para fins não comerciais, atribuindo o devido crédito de autoria e publicação inicial neste periódico desde que adotem a mesma licença, compartilhar igual. Os autores têm autorização para assumir contratos adicionais separadamente, para distribuição não exclusiva da versão do trabalho publicada neste periódico (ex.: publicar em repositório institucional, em site pessoal, publicar uma tradução, ou como capítulo de livro), com reconhecimento de autoria e publicação inicial neste periódico, desde que para fins não comerciais e compartilhar com a mesma licença.

\section{PUBLISHER}

Universidade Federal de Santa Catarina. Programa de Pós-Graduação em Educação Física. LaboMídia - Laboratório e Observatório da Mídia Esportiva. Publicado no Portal de Periódicos UFSC. As ideias expressadas neste artigo são de responsabilidade de seus autores, não representando, necessariamente, a opinião dos editores ou da universidade.

\section{EDITORES}

Mauricio Roberto da Silva, Giovani de Lorenzi Pires, Rogério Santos Pereira.

\section{HISTÓRICO}

Recebido em: 30 de Junho de 2018.

Aprovado em: 23 de Outubro de 2018. 